\title{
The management of acute lateral ankle sprains: a survey of South African surgeons and best evidence available
}

\author{
Wever GS1, McCollum G² \\ ${ }_{1}^{1} \mathrm{MBChB}($ Stell); Registrar, Orthopaedic Surgery, Groote Schuur Hospital, University of Cape Town \\ 2 MBChB(UCT), Dip Pec(SA), MMed(UCT), FCOrth(SA); Consultant Orthopaedic and Foot and Ankle Surgeon, Groote Schuur Hospital
}

Corresponding author: Dr Graham McCollum, Department of Orthopaedic Surgery, H49 Old Main Building, Groote Schuur Hospital, Anzio Road, 7925 , Observatory, Cape Town; email: grahammac@discoverymail.co.za; tel: (021) 4045108

\begin{abstract}
Introduction: Ankle sprains remain the single most frequent injury in modern sports with increasing evidence that it is not as innocuous as previously thought. Conservative treatment options include various forms of immobilisation such as casts, moonboots and stirrup braces, followed by a rehabilitation period involving different modalities. Despite clinical evidence there seems to be a divergence between research and practice with an increase in acute surgical repair especially with regard to professional athletes. The aim of the study was to assess the approach on management of acute ankle sprains by orthopaedic surgeons in South Africa, by means of a descriptive cross-sectional survey analysis.
\end{abstract}

Methods: This was a two-part study. First, a questionnaire was emailed to participating orthopaedic surgeons, consisting of eight treatment options for a grade three lateral ankle sprain in a non-professional athlete. Secondly, a literature review was undertaken to establish the current best practice concerning ankle sprain management.

Results: A total of 129 responses was received out of the 719 that were sent out. Surgical repair was offered in $24(19 \%)$. Conservative treatment including either cast or moonboot for a period of six weeks was chosen by $49(38 \%)$ and two to four weeks by $55(43 \%)$ as their preferred treatment. Only 39 (30\%) of responding South African Orthopaedic Association members chose a short period of immobilisation followed by functional rehabilitation in accordance with the current best evidence available, based on the literature review done.

Conclusion: Despite good clinical evidence, there seems to be a lack of consensus in the management of grade three lateral ankle sprains.

Level of evidence: Level 5

Key words: ankle sprain, treatment, acute, ligament injury, management

Citation: Wever GS, McCollum G. The management of acute lateral ankle sprains: a survey of South African surgeons and best evidence available. SA Orthop J 2018;17(2):35-39. http://dx.doi.org/10.17159/2309-8309/2018/v17n2a6

Editor: Dr LC Marais, University of KwaZulu-Natal

Received: August 2017

Accepted: December 2017

Published: May 2018

Copyright: () 2018 Wever GS. This is an open-access article distributed under the terms of the Creative Commons Attribution Licence, which permits unrestricted use, distribution and reproduction in any medium, provided the original author and source are credited.

Funding: Both authors confirm that no benefits of any form have been received from any party related directly or indirectly to the subject of this article.

Conflict of interest: The authors declare they have no conflicts of interest or competing interests to disclose that are directly or indirectly related to the research. 


\section{Introduction}

Musculoskeletal problems are a significant health problem and burden. Ankle injuries are extremely common during sports and activities. Eighty-five per cent of ankle injuries are sprains and of these, 95\% involve mainly the lateral ankle ligament complex. ${ }^{1}$ Grade one and two lateral ankle sprains (LAS) remain the most prevalent injury. However, recent evidence shows that there is no such thing as a simple sprain. ${ }^{2}$ Verhagen et al. reported a calculated total cost of 360 Euro per injured person in $2005,{ }^{3}$ while Feger et al. reported a financial burden of 152 million USD per year of which 88\% was spent on diagnosis and not actual treatment. ${ }^{4}$ Acute LAS significantly affect daily activity and cause a high incidence of absenteeism in both work and physical activities adding to the burden. ${ }^{5}$ Impact measured in disability-adjusted life-years (DALY), which is a measure of overall disease burden expressed as the number of years lost due to a certain disability, has increased by $50 \%$ from 2000 to $2010{ }^{6}$ Although reported that over $90 \%$ return to activity after ten days, $72 \%$ will have persistent symptoms at six months and $45 \%$ would not have fully recovered by three years. ${ }^{7}$ Strong evidence suggests that athletes in the first year of competition have twice the risk of suffering a recurrent LAS and of these, 50\% will develop chronic symptoms. ${ }^{8}$ Despite compelling evidence of the importance of managing acute LAS as well as clear guidelines from numerous systematic reviews and meta-analyses, 90\% of patients seeking medical care are managed incorrectly. 2,4,7,9-11

Simpson et al. did a descriptive cross-sectional survey looking at whether physiotherapists follow evidence-based guidelines when treating LAS. They found that between 49 and $91 \%$ used interventions for which there was no evidence. ${ }^{12}$ Our question: Do all orthopaedic surgeons in South Africa treat acute LAS according to best current evidence? Thus, the null hypothesis is that there is no difference between current evidence-based guidelines and the management that orthopaedic surgeons will choose to treat an acute LAS.

\section{Methods}

A descriptive cross-sectional survey analysis was performed to assess the approach to management of acute LAS by orthopaedic surgeons in South Africa. An anonymous questionnaire emailed to members of the South African Orthopaedic Association (SAOA) on the current management of acute LAS consisted of eight treatment options for a grade three lateral ankle sprain in a non-professional athlete (Figure 1). The questions focused on the surgeon's treatment in the first six weeks after the sprain. Published research concerning lower back pain has utilised case studies of typical clinical presentations to

\section{Management of ankle sprain}

\section{Clinical scenario}

A 28-year-old active male presents to your practice after an ankle sprain sustained while playing soccer. You diagnose him with a grade 3 isolated acute lateral ankle sprain. Please choose from the list below the most appropriate answer as to your initial management plan for him.

a. Surgery with acute repair of the ATFL and CFL

b. Plaster cast for 6 weeks

c. Plaster cast for $2-4$ weeks

d. Moonboot for 6 weeks

e. Moonboot for 2 weeks

f. Short period of immobilisation followed by functional rehabilitation

g. Ankle brace (e.g. stirrup brace) only

h. Compression bandage

Please mark your answer with a tick. elicit information about the selection of management approaches. ${ }^{13}$ This method was also selected for the case used in this study, as it reflects the difference in orthopaedic surgeons' choices of interventions, rather than the differences in presentation of the patient.

A similar survey of physiotherapists was done and validated by a panel of experts in the field to ensure that the answers were objective and non-biased..$^{12}$ Ethics clearance was obtained from the Faculty of Health Sciences Human Research Ethics Committee (081/2017). The author also did an in-depth search of electronic databases including EBSCOhost, Scopus, Google Scholar, Science Direct, Springer and Web of Science regarding the management of acute lateral ankle sprains. Search words included the following: 'ankle sprain', 'ligament injury', 'acute', 'lateral ankle injury', 'treatment', 'management', with the focus on current research, to review the current best practice regarding the management approach of LAS.

\section{Results}

A total of 719 SAOA members were invited to participate, with 129 of the distributed questionnaires returned. Five hundred and three questionnaires were not returned, 77 questionnaires were not delivered to the recipients and ten surgeons declined filling in the questionnaire. Twenty-four (19\%) surgeons chose acute surgical repair compared to 105 that chose a conservative approach

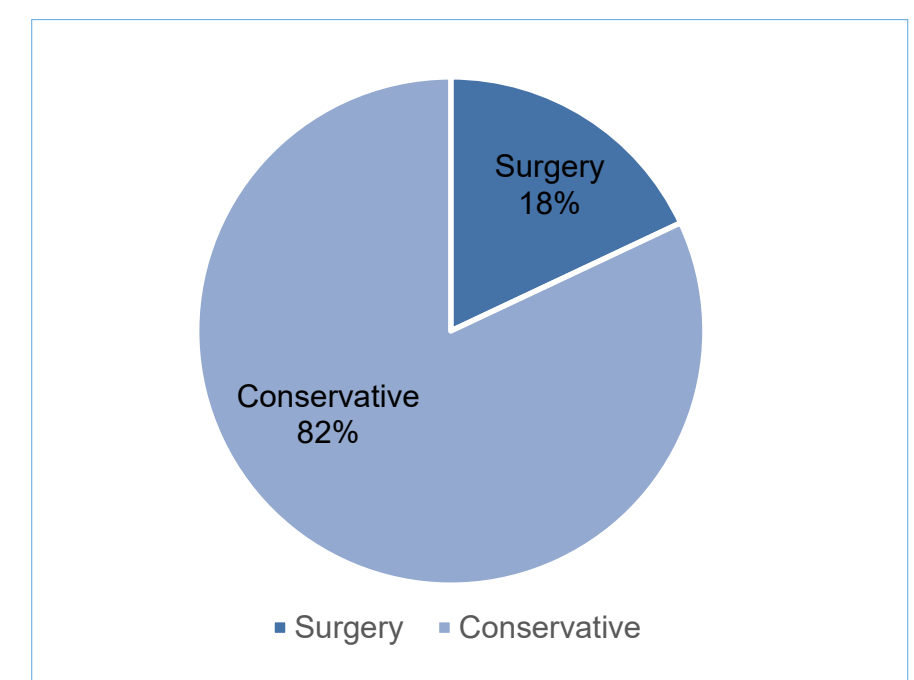

Figure 2. Surgery vs conservative treatment

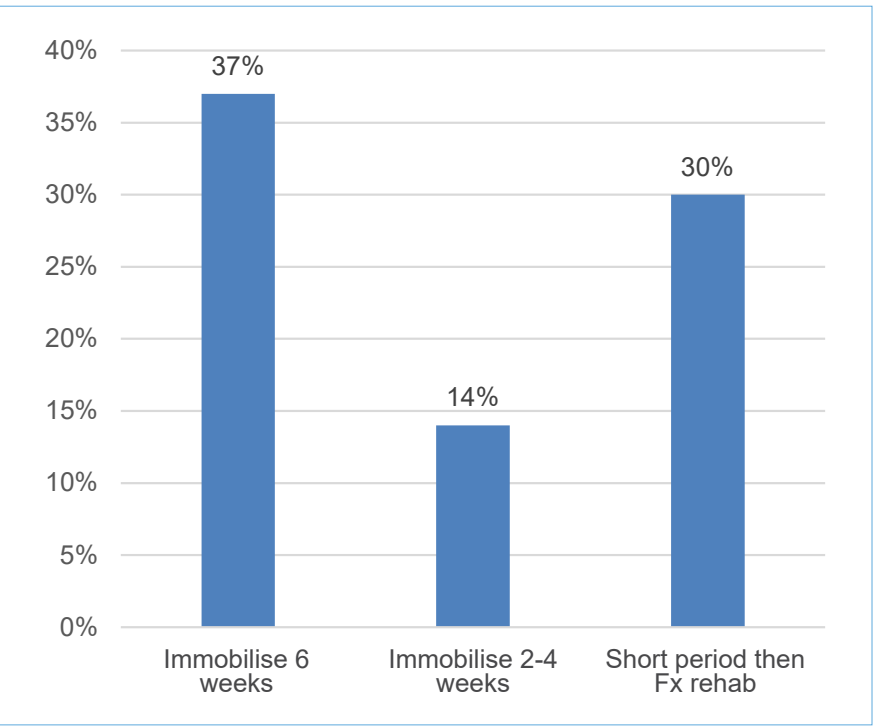

Figure 3. Period of immobilisation

Figure 1. Questionnaire 


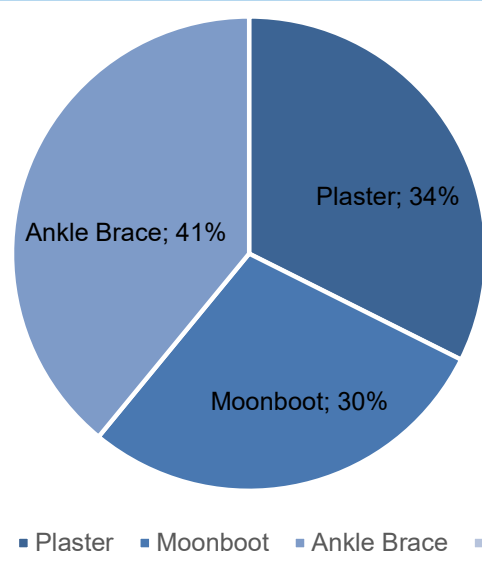

Figure 4. Period of immobilisation

(Figure 2). Forty-nine (38\%) recommended a six-week period of immobilisation in either a cast or moonboot compared to 56 (53\%) recommending a shorter period. Only $39(30 \%)$ of surgeons chose a short period of immobilisation followed by functional rehabilitation in accordance with the current best evidence available (Figure 3). Regarding the type of immobilisation, the majority chose an ankle brace (39\%) followed by below-knee plaster of Paris cast (32\%) and moonboot (29\%) (Figure 4). None of the orthopaedic surgeons chose to use compressive bandage alone.

\section{Discussion}

Simpson et al. noted in a survey done under physiotherapists that many treatment modalities are still used despite evidence showing minimal to no benefit. ${ }^{12}$

Ligaments fail usually under tensions greater than their yield point and this causes either partial or complete tears. The body's response to this is through a complex inflammatory response that involves three distinct phases overlapping each other.

The acute inflammatory phase begins within minutes of injury and continues over the next 48 to 72 hours. During this phase, a haematoma forms at the site of injury and platelet cells interact with matrix components. Growth factors are released which are necessary for healing and provide a platform on which many cellular events occur.

The proliferative/repair phase begins when immune cells release various growth factors and cytokines, which initiate fibroblast proliferation to rebuild the ligament tissue matrix. Initially tissue appears as disorganised scar tissue with more blood vessels, fat cells, fibroblastic and inflammatory cells than normal ligament tissue.

Subsequently a complex healing process occurs over several weeks, as follows: Fibroblast cells deposit various types of collagen, proteoglycans, other proteins and glycoproteins to the matrix. The collagen becomes aligned with the long axis of the ligament during this time; however, the newly formed type of collagen fibrils are abnormal and smaller in diameter than normal ligament tissue. After a few weeks, the remodelling phase starts in which collagen maturation occurs. This can last for months to years after the initial injury. With time, the tissue matrix starts to resemble normal ligament tissue. Evidence does show that the new tissue is grossly, histologically, biochemically, and biomechanically inferior to the normal tissue. ${ }^{14} \mathrm{~A}$ grade three LAS (Table I) typically means that the anterior talofibular ligament (ATFL) and calcaneofibular ligament (CFL) is completely torn and that the posterior talofibular ligament (PTFL) is partially torn. ${ }^{15}$

It has been shown that immobilisation for prolonged periods leads to muscle wasting and joint stiffness. There is a decrease in the tensile strength of ligaments as well as collagen fibril numbers and thickness. Fibroblasts mainly produce type three collagen after
Table I: LAS classification

\begin{tabular}{|l|c|c|c|}
\hline Gigament & $\begin{array}{c}\text { Ecchymosis } \\
\text { and swelling }\end{array}$ & $\begin{array}{c}\text { Pain with } \\
\text { weight bearing }\end{array}$ \\
\hline Grade 1 & None/Stretch & Minimal & Normal \\
\hline Grade 2 & Partial & Moderate & Mild \\
\hline Grade 3 & Complete & Severe & Severe \\
\hline
\end{tabular}

an injury compared to type one collagen which makes up $85 \%$ of the collagen in normal ligaments. ${ }^{16}$ Nash et al. point out that early mobilisation increases blood flow, and reduces muscle atrophy, adhesions and joint stiffness, which in turn leads to decreased pain. ${ }^{17}$ This effect is called causal histogenesis, where functional stress is needed for remodelling of connective tissue. ${ }^{2}$ Kerkhoffs et al. showed in a meta-analysis that exercise is associated with less instability and earlier return to function. ${ }^{18}$ Current evidence recommend early functional rehabilitation is better than immobilisation for grade one and two LAS and a short period of immobilisation (seven to ten days) followed by functional rehabilitation for grade three LAS. 2,5,9,1922 In our survey we found that nearly $40 \%$ of orthopaedic surgeons chose six weeks immobilisation as their initial management. With regard to different external supports, the Cochrane review by Kerkhoffs et al. showed that lace-up ankle braces are superior to semi-rigid braces, elastic bandage and tape in the short term. Tape also tends to have more skin problems associated with it. ${ }^{23}$ Lardenoye et al. found increased patient satisfaction regarding braces compared to tape, but no difference in functional outcome and pain. ${ }^{24}$ Beynnon et al. found that the Air-Stirrup $®$ brace with elastic wrap led to return to function in half the time as compared to wrap or bracing alone. ${ }^{25}$ They also found no difference in casting or Air-Stirrup bracing for the first ten days in grade three LAS. A prospective randomised study including 186 patients by Prado et al. compared functional braces with a walking boot and found that the brace resulted in earlier return to activity. ${ }^{10}$ Doherty et al.'s metaanalysis of 46 systematic reviews containing 309 studies reported a lower incidence of re-injury with the use of braces or tape compared to no support. They recommend wearing a brace during sporting activities for a minimum of six months with benefit up to one year with lace-up braces better than semi-rigid braces. ${ }^{11}$ In our survey only $39 \%$ of SAOA members used ankle braces in managing acute LAS.

The National Athletic Trainers Association (NATA) recommendations advised caution in the use of non-steroidal anti-inflammatory drugs (NSAIDs) because of possible decrease in the tensile strength of the healing ligaments. They found that military recruits returned to training earlier, but noted greater instability and swelling after 14 days, most likely due to the analgesic effects that allowed return before the ligaments were healed. ${ }^{20}$ Hauser et al. did a review of treatment options in ligament injuries in general and found that, although effective in decreasing pain and swelling for the first six to eight weeks, non-steroidal anti-inflammatory drugs (NSAIDs) did inhibit the histological, biochemical and biomechanical properties of ligament healing. ${ }^{16}$ Van den Bekerom et al. ${ }^{26}$ reported in a meta-analysis of 22 trials that oral and topical NSAIDS are superior to placebo regarding pain and swelling in the short term. They did conclude that there was a low number of studies with a lack of methodological quality and small sample sizes but still recommended the use thereof. Regarding platelet-rich therapies it is thought that they could enhance the healing process due to the production of growth factors; however, numerous randomised controlled trials as well as a Cochrane review have shown no benefit regarding pain and function in both the short and long term. ${ }^{27,28}$ Petrella et al. and Jakobs et al. both showed in prospective randomised controlled trials that hyaluronic acid per articular injections results in earlier return to activity, decreased pain and increased patient satisfaction. However the literature on viscoelastic injections for acute LAS is limited. ${ }^{29,30}$ Cryotherapy is part of the so-called RICE (rest, ice, compression, 
elevation) treatment. NATA recommendations noted that there is limited strong evidence for using cryotherapy but no evidence not to apply it. It is thought to decrease pain through reduced nerve conduction and muscle spasm and swelling through vasoconstriction of vessels leading to decreased permeability, but is only effective 15 to 30 minutes after treatment. Bleakley et al. compared two different cryotherapy regimens based on the duration of application and found no difference in functional status, swelling or pain at rest. ${ }^{31}$ Regarding manual therapy Ojha et al. did a systematic review and concluded that early manual therapy decreases total episode cost. ${ }^{32}$ Although the mechanism by which manual therapy works is unknown, Cleland et al. reported it to be superior to home-based exercises with respect to pain and function. ${ }^{33}$ Hubbard reported, in only anecdotal evidence in the form of case studies, improved motion but only after multiple sessions. ${ }^{19,34}$ Evidence to support manual therapy is only moderate regarding effects on swelling and improved motion. 6,31 Seventy-eight per cent of physiotherapists in a survey by Guillodo et al. ${ }^{35}$ indicated that they would use it; however, Kerkhoffs et al. showed in a systematic review that evidence is limited regarding the benefits and that most positive effects disappeared two weeks after the injury, and thus recommended against using manual therapy. ${ }^{36}$ Evidence also shows that ultrasound and laser therapy has no benefit and only adds extra cost. 11,22,37-39 Neuromuscular training is defined as training to enhance unconscious motor responses by stimulating both afferent signals and central mechanisms responsible for dynamic joint control. ${ }^{40}$ Freeman's concept was that it serves as an adjunct to functional treatment since joint injury results in proprioceptive deficit that prevents functional recovery and risks long term instability. ${ }^{41}$ It is been shown that neuromuscular and proprioceptive training decreases re injury rates and functional instability. ${ }^{9}$ Petersen et al. concluded in their systematic review that proprioceptive and neuromuscular training can be used in an effort to decrease future risk of re-sprain using mainly the 2Fit trial that included 522 participants, which was more powered than the studies by van Rijn et al. and Bleakley with a mere 102 participants. $2,42,43$

In our survey, we found that one in five orthopaedic surgeons (20\%) would do an acute surgical repair, which is in contrast to current best practice. Kerkhoffs et al. in their Cochrane review, comparing surgery versus conservative treatment for acute lateral ankle ligament injuries, failed to demonstrate a clear superior treatment approach. ${ }^{23}$ There was evidence for longer recovery times, higher incidence of ankle stiffness, impaired ankle mobility and more complications in the surgical treatment group. Doherty et al. did a meta-analysis including 46 systematic reviews consisting of 309 studies. ${ }^{11}$ Most randomised controlled trials used function, determined as time taken to return to work/activity, as their outcome. None of the reviews reported on the primary outcome of recurrence. The consensus regarding surgery is that it is not indicated prior to a conservative treatment trial, persistent symptoms and on an individual basis. Several reviewers further reported the propensity for a surgical intervention to have a higher risk of complications, including issues with wound healing, infection, dystrophy, and iatrogenic nerve injury leading to sensory deficit and paraesthesia compared to conservative treatment. ${ }^{11,18,22}$ Van den Bekerom et al. however did note that early surgical repair in professional athletes can be beneficial. In the narrative review article, they noted that objective instability measured as talar tilt or the anterior draw test was a predictor of recurrent instability and that surgery decreases this. This outcome is dependent on multiple factors including patient factors and access to an expert orthopaedic surgeon. ${ }^{22}$ White et al. more recently reported on a series of 42 professional athletes, median age of 22 years, that underwent a modified Broström repair for grade three LAS. They found that surgical management 'led to a more predictable return to sport' which is essential in professional athletes. Of note is also a $25 \%$ incidence of associated injuries such as osteochondral lesions that were identified and successfully treated during surgery. ${ }^{44}$ The survey was limited in the sense that no demographical data was collected to comment on experience or background and the fact that the response rate to the survey was so low.

\section{Conclusion}

Regarding the management of acute LAS, evidence seem to support lace-up braces in grade one and two ankle sprains. In grade three acute LAS, one can consider a short period of immobilisation followed by a lace-up brace. A phase-adapted functional rehabilitation programme is recommended, incorporating neuromuscular training which has specific benefits on the re-sprain rates. With respect to surgery there is a need for sufficiently powered, high quality randomised trials, and currently there is limited evidence for the young professional athlete. In the South African setting, taking cost and resources into consideration, the treatment algorithm for grade three LAS could be as follows: Wear a lace-up brace for the first week, which is much cheaper than the moonboot that is often given, but if not available place in a below-knee cast and prescribe NSAIDs as part of the pain regimen. From week two start with functional rehabilitation, referring to the physiotherapist. Specific instruction should include proprioceptive and neuromuscular training with early weightbearing as able, protecting the ankle from excessive inversion. Advise the patient to continue the neuromuscular training and wearing of the lace-up brace to prevent recurring injuries.

In our survey we found that less than half of orthopaedic surgeons follow the current best evidence in managing acute LAS regarding type and duration of immobilisation. This study shows a difference in the management of acute ankle sprains regarding current evidence and clinical practice.

\section{Ethics statement}

Ethics clearance was obtained from our institution's Faculty of Health Sciences Human Research Ethics Committee (081/2017).

\section{Acknowledgements}

Simon Rauch and lan Douglass for assisting with the questionnaire and emailing.

\section{References}

1. Pellow JE, Brantingham JW. The efficacy of adjusting the ankle in the treatment of subacute and chronic grade I and grade II ankle inversion sprains. Journal of Manipulative and Physiological therapeutics. 2001;24(1):17-24.

2. Petersen W, Rembitzki IV, Koppenburg AG, Ellermann A, Liebau C, Brüggemann GP, et al. Treatment of acute ankle ligament injuries: a systematic review. Archives of Orthopaedic and Trauma Surgery. 2013;133(8):1129-41

3. Verhagen E, Van Tulder $M$, van der Beek AJ, Bouter L, Van Mechelen W. An economic evaluation of a proprioceptive balance board training programme for the prevention of ankle sprains in volleyball. British Journal of Sports Medicine. 2005;39(2):111-15.

4. Feger MA, Glaviano NR, Donovan L, Hart JM, Saliba SA, Park JS, et al. Current trends in the management of lateral ankle sprain in the United States. Clinical Journal of Sport Medicine. 2017 Mar;27(2):145-52.

5. O'Connor SR, Bleakley CM, Tully MA, McDonough SM. Predicting functional recovery after acute ankle sprain. Plos One. 2013;8(8):e72124-e.

6. Eisenhart AW, Gaeta TJ, Yens DP. Osteopathic manipulative treatment in the emergency department for patients with acute ankle injuries. The Journal of the American Osteopathic Association. 2003;103(9):417-21.

7. Gribble PA, Bleakley CM, Caulfield BM, Docherty CL, Fourchet F, Fong DT-P, et al. 2016 consensus statement of the International Ankle Consortium: prevalence, impact and long-term consequences 
of lateral ankle sprains. British Journal of Sports Medicine. 2016:bjsports-2016-096188.

8. Hertel J. Functional anatomy, pathomechanics, and pathophysiology of lateral ankle instability. Journal of Athletic Training. 2002;37(4):364.

9. Bleakley CM, McDonough SM, MacAuley DC. Some conservative strategies are effective when added to controlled mobilisation with external support after acute ankle sprain: a systematic review. Australian Journal of Physiotherapy. 2008;54(1):7-20.

10. Prado MP, Mendes AAM, Amodio DT, Camanho GL, Smyth NA, Fernandes TD. A comparative, prospective, and randomized study of two conservative treatment protocols for first-episode lateral ankle ligament injuries. Foot and Ankle International. 2014;35(3):201-206.

11. Doherty C, Bleakley C, Delahunt E, Holden S. Treatment and prevention of acute and recurrent ankle sprain: an overview of systematic reviews with meta-analysis. British Journal of Sports Medicine. 2016:bjsports-2016-096178.

12. Simpson $H$, Crous L, Louw $Q$. Physiotherapy for acute ankle sprains: How do we compare to evidence based clinical guidelines? South African Journal of Physiotherapy. 2014;70(2):19-26.

13. Mikhail C, Korner-Bitensky N, Rossignol M, Dumas J-P. Physical therapists' use of interventions with high evidence of effectiveness in the management of a hypothetical typical patient with acute low back pain. Physical Therapy. 2005;85(11):1151-67.

14. Hauser RA, Dolan EE. Ligament injury and healing: an overview of current clinical concepts. Journal of Prolotherapy. 2011;3(4):836-46.

15. Kannus P, Renstrom P. Treatment for acute tears of the lateral ligaments of the ankle. J Bone Joint Surg Am. 1991;73(2):305-12.

16. Hauser R, Dolan E, Phillips $H$, Newlin A, Moore R, Woldin B. Ligament injury and healing: a review of current clinical diagnostics and therapeutics. The Open Rehabilitation Journal. 2013;6(1).

17. Nash CE, Mickan SM, Del Mar CB, Glasziou PP. Resting injured limbs delays recovery: a systematic review. Journal of Family Practice. 2004;53(9):706.

18. Kerkhoffs GM, Struijs PA, Marti RK, Assendelft WJ, Blankevoort L, Van Dijk C. Different functional treatment strategies for acute lateral ankle ligament injuries in adults. The Cochrane Library. 2002.

19. Hubbard TJ, Wikstrom EA. Ankle sprain: pathophysiology, predisposing factors, and management strategies. Open Access Journal of Sports Medicine. 2010;1:115-22.

20. Kaminski TW, Hertel J, Amendola N, Docherty CL, Dolan MG, Ty Hopkins J, et al. National Athletic Trainers' Association Position Statement: Conservative Management and Prevention of Ankle Sprains in Athletes. Journal of Athletic Training (Allen Press). 2013;48(4):528-45.

21. Lamb SE, Marsh JL, Hutton JL, Nakash R, Cooke MW. Mechanical supports for acute, severe ankle sprain: a pragmatic, multicentre, randomised controlled trial. The Lancet.373(9663):575-81.

22. van den Bekerom MP, Kerkhoffs GM, McCollum GA, Calder JD, van Dijk CN. Management of acute lateral ankle ligament injury in the athlete. Knee Surgery, Sports Traumatology, Arthroscopy. 2013;21(6):1390-95.

23. Kerkhoffs G, Kennedy JG, Calder JD, Karlsson J. There is no simple lateral ankle sprain. Editorial. Knee Surgery, Sports Traumatology, Arthroscopy. 2016;4.

24. Lardenoye S, Theunissen E, Cleffken B, Brink PR, de Bie RA, Poeze $M$. The effect of taping versus semi-rigid bracing on patient outcome and satisfaction in ankle sprains: a prospective, randomized controlled trial. BMC Musculoskeletal Disorders. 2012;13(1):81.

25. Beynnon BD, Renström PA, Haugh L, Uh BS, Barker H. A prospective, randomized clinical investigation of the treatment of first-time ankle sprains. The American Journal of Sports Medicine. 2006;34(9):1401-12.

26. van den Bekerom MP, Sjer A, Somford MP, Bulstra GH, Struijs PA, Kerkhoffs GM. Non-steroidal anti-inflammatory drugs (NSAIDs) for treating acute ankle sprains in adults: benefits outweigh adverse events. Knee Surgery, Sports Traumatology, Arthroscopy. 2015;23(8):2390-99.

27. Rowden A, Dominici P, D'Orazio J, Manur R, Deitch K, Simpson S, et al. Double-blind, randomized, placebo-controlled study evaluating the use of platelet-rich plasma therapy (PRP) for acute ankle sprains in the emergency department. The Journal of Emergency Medicine. 2015;49(4):546-51.

28. Moraes VY, Lenza M, Tamaoki MJ, Faloppa F, Belloti JC. Platelet rich therapies for musculoskeletal soft tissue injuries. The Cochrane Library. 2014.

29. Petrella RJ, Petrella MJ, Cogliano A. Periarticular hyaluronic acid in acute ankle sprain. Clinical Journal of Sport Medicine. 2007;17(4):251-57.

30. Jakobs C, Wirbel R, Korner J. Influence of hyaluronic acid on the clinical course of ankle sprains. Clin Sport Med Int (CSMI). 2015;8:1-5.

31. Bleakley CM, McDonough SM, MacAuley DC. Cryotherapy for acute ankle sprains: a randomised controlled study of two different icing protocols. British Journal of Sports Medicine. 2006;40(8):700-705.

32. Ojha HA, Wyrsta NJ, Davenport TE, Egan WE, Gellhorn AC. Timing of physical therapy initiation for nonsurgical management of musculoskeletal disorders and effects on patient outcomes: a systematic review. Journal of Orthopaedic \& Sports Physical Therapy. 2016;46(2):56-70.

33. Cleland JA, Mintken P, McDevitt A, Bieniek M, Carpenter K, Kulp $\mathrm{K}$, et al. Manual physical therapy and exercise versus supervised home exercise in the management of patients with inversion ankle sprain: a multicenter randomized clinical trial. Journal of Orthopaedic \& Sports Physical Therapy. 2013;43(7):443-55.

34. Hubbard TJ, Hicks-Little CA. Ankle ligament healing after an acute ankle sprain: an evidence-based approach. Journal of Athletic Training. 2008;43(5):523-29.

35. Guillodo Y, Le Goff A, Saraux A. Adherence and effectiveness of rehabilitation in acute ankle sprain. Annals of Physical and Rehabilitation Medicine. 2011;54(4):225-35.

36. Kerkhoffs GM, van den Bekerom M, Elders LA, van Beek PA, Hullegie WA, Bloemers GM, et al. Diagnosis, treatment and prevention of ankle sprains: an evidence-based clinical guideline. British Journal of Sports Medicine. 2012;46(12):854-60.

37. de Bie RA, de Vet HC, Lenssen TF, van den Wildenberg FA, Kootstra G, Knipschild PG. Low-level laser therapy in ankle sprains: a randomized clinical trial. Archives of Physical Medicine and Rehabilitation. 1998;79(11):1415-20.

38. van den Bekerom MPJ, van der Windt D, ter Riet G, van der Heijden GJ, Bouter LM. Therapeutic ultrasound for acute ankle sprains. Cochrane Database of Systematic Reviews. 2011(6).

39. van der Windt DA, van der Heijden GJ, Van den Berg S, ter Riet G, De Winter AF, Bouter LM, et al. Therapeutic ultrasound for acute ankle sprains. The Cochrane Library. 2002.

40. Hübscher M1, Zech A, Pfeifer K, Hänsel F, Vogt L, Banzer W. Neuromuscular training for sports injury prevention: a systematic review. Med Sci Sports Exerc. 2010 Mar;42(3):413-21.

41. Freeman M. Instability of the foot affer injuries to the lateral ligament of the ankle. Bone \& Joint Journal. 1965;47(4):669-77.

42. Van Rijn RM, Van Os AG, Bernsen RM, Luijsterburg PA, Koes BW, Bierma-Zeinstra SM. What is the clinical course of acute ankle sprains? A systematic literature review. The American Journal of Medicine. 2008;121(4):324-31. e7.

43. Bleakley CM, O'Connor SR, Tully MA, Rocke LG, MacAuley DC, Bradbury I, et al. Effect of accelerated rehabilitation on function after ankle sprain: randomised controlled trial. BMJ. 2010;340:c1964.

44. White WJ, McCollum GA, Calder JD. Return to sport following acute lateral ligament repair of the ankle in professional athletes. Knee Surgery, Sports Traumatology, Arthroscopy. 2016;24(4):1124-29. 